\title{
Numerical Investigation of Effect of Casting Speed on Flow Characteristics of Molten Steel in Multistrand Tundish
}

\author{
Fei HE, Haijun WANG* and Zhenghai ZHU \\ School of Metallurgical Engineering, Anhui University of Technology, Ma'anshan, Anhui, 243002 P.R. China. \\ (Received on December 12, 2018; accepted on February 5, 2019; J-STAGE Advance published date: \\ April 28, 2019)
}

\begin{abstract}
Casting speed is one of the key factors affecting flow characteristics in the tundish. This paper gives a detailed numerical investigation for the effect of casting speed on flow characteristics in a five-strand tundish. Firstly, a quantitative evaluation method of flow characteristics (such as dead region, short-circuit flow and flow uniformity among multiple strands) is proposed. And then, by using the method, the effect of the cases (such as reducing to the same casting speed for each strand, closing one or two strands, etc.) on flow characteristics in the case of reducing throughput is analyzed. The results show that the case of closing strands 2 and 4 has the best flow characteristics, and not only dead region volume is smaller, but also the flow difference among multiple strands is also smaller. Meanwhile, in view of slower flow and bigger dead region near the far-strand of the tundish and large difference for flow characteristics between the far-strand and other strands, the effect of increasing the far-strand's casting speed on improving the overall flow characteristic in the tundish is also analyzed. The results show that, increasing the far-strand's casting speed can significantly reduce dead region proportion and flow difference among multiple strands, and in the case of the same throughput, the short-circuit flow does not change much. In the case of increasing the same throughput, flow characteristics in the tundish for only increasing the far-strand's casting speed are better than that for increasing casting speed of each strand simultaneously.
\end{abstract}

KEY WORDS: casting speed; tundish; numerical simulation; flow characteristic; dead region.

\section{Introduction}

In continuous casting of steel, tundish is an important intermediate vessel between ladle and mold. It not only has the function of stabilizing static pressure of molten steel, distributing and storing a certain amount of molten steel to realize sequence continuous casting, but also plays an important metallurgical role of promoting the homogenization of molten steel temperature and composition and the floatation and removal of nonmetallic inclusions. So good or bad of flow characteristics of molten steel in tundish will directly affect the cleanliness of steel and the quality of billet, and even affect the stability of continuous casting production. It is of great significance to obtain ideal tundish flow characteristics. ${ }^{1-3)}$

Compared with single-strand and two-strand tundish, the rule of fluid flow in a multistrand tundish is more complicated, which leads to many problems in actual production process. For example, there is a larger temperature difference of molten steel among multiple strands. Molten steel coming from ladle shroud toward the closest strand provides a higher temperature in the corresponding mold, which could easily cause centerline segregation and breakout accident. Meanwhile, molten steel temperature in the

\footnotetext{
* Corresponding author: E-mail: whjchina@yeah.net

DOI: https://doi.org/10.2355/isijinternational.ISIJINT-2018-835
}

farthest strand is lower, which could easily lead to nozzle clogging. Therefore, for multistrand tundish, the objective is not only to have an ideal flow characteristic in each strand, but also to have consistent flow characteristics among multiple strands. At present, most studies mainly focus on the design and optimization of flow control devices in multistrand tundishes. ${ }^{4-10)}$ Reasonable flow control devices are an important guarantee to obtain ideal flow characteristic. However, due to the structural particularity of multistrand tundish, the improvement of overall flow characteristics in the tundish is not limited only by optimization of the flow control devices. There are many casting process factors that also have an important impact on flow characteristics.

Casting speed is one of the key factors affecting flow characteristics in the tundish. Cwudziński ${ }^{11)}$ investigated the effect of casting speed on the flow hydrodynamics of liquid steel in a single-nozzle tundish. Raghavendra ${ }^{12)}$ studied the effect of inlet flow rate (namely throughputs) on the efficiency of inclusion separation by mathematical modeling for a four strand tundish. Actually, the inlet flow rate reflects the level of casting speed. Meanwhile, some scholars ${ }^{13-16)}$ have also investigated the effect of blockage of one strand, two strands and multiple strands on fluid flow behaviour in a multistrand tundish by physical simulation and numerical simulation. Their aim is to find the most preferred options about which of the strands should be closed when the plant operation needs to do so. Here, blockage of strands 
is that the casting speed of the strands are zero $\mathrm{m} / \mathrm{min}$. In other words, the effect of blockage of strands on fluid flow behavior in the tundish is also an effect of casting speed on the flow behavior.

However, for multistrand tundish, the effects of casting speed on flow characteristics have not been investigated in many cases. In this paper, for a plant five-strand tundish, we have investigated the effect of different casting speed combinations of strands on flow characteristics in the case of reducing throughput. When the plant needs to reduce the throughput, the selection of reducing the casting speed of each strand at the same time, or closing one strand, two strands or other is crucial and should be mainly based on flow characteristics. Meanwhile, we have also investigated the effect of increasing the far-strand's casting speed on flow characteristics. For the tundish with optimized flow control device, there are still the problems of slower flow and bigger dead region near the far-strand and large difference for flow characteristics between far-strand and other strands, and we tried to further improve overall flow characteristics of the multistrand tundish by increasing the far-strand's casting speed. In addition, to better conduct the above investigation, a quantitative evaluation method of fluid flow characteristics for multistrand tundish is proposed from the aspects of dead zone, short circuit flow and flow uniformity among multiple strands.

\section{Description of Plant Tundish}

The plant tundish is a symmetrical T-type five-strand billet caster tundish. Figure 1(a) is schematic top view of the tundish. The flow control devices for the tundish have been optimized by water modeling and numerical simulation in the previous study. ${ }^{10)} \mathrm{A}$ better flow control device is the U-type baffle with deflector holes and round turbulence inhibitor in Fig. 1. The location of the U-type baffle in the tundish can be seen from Fig. 1(a). Figure 1(b) shows front and top views of the U-type baffle. To better describe the deflector holes on the baffle, the view from M-M, top and side views of M-M are also provided in Fig. 1(b). Figure 1(c) shows top and front views of the turbulence inhibitor. The turbulence inhibitor is located at the impact point in Fig. 1(a).

The tundish's capacity is about 40 tons. Operating liquid level height is $800 \mathrm{~mm}$. Diameter of ladle shroud is $80 \mathrm{~mm}$. Submergence depth of the shroud is $180 \mathrm{~mm}$. Diameter of each outlet is $24 \mathrm{~mm}$. Steel grades smelted in the tundish are mainly the high quality carbon construction steel, alloyed structure steel, cold heading steel, bearing steel and gear steel, etc. The billet section is $200 \times 200 \mathrm{~mm}^{2}$, and the corresponding casting speed ranges from $0 \mathrm{~m} / \mathrm{min}$ to $2.1 \mathrm{~m} /$ min. Usually, the working casting speed is about $1.4 \mathrm{~m} / \mathrm{min}$.

\section{Numerical Simulation}

\subsection{Mathematical Models and Solution Procedure}

Considering that the flow of molten steel in the tundish is in the case of complex geometrical shape and physical conditions, and is not the flow under ideal conditions, in the numerical simulation, it is assumed that the molten steel is a viscous and incompressible Newtonian fluid, and the influence of tundish cover powder and slag layer on molten steel flow is ignored, and the influence of liquid level fluctuation is also ignored. The molten steel flow in the tundish can be regarded as a three-dimensional single-phase steady turbulent flow. But the mass transfer is an unsteady process. The basic control equations for the flow of molten steel in the tundish include: continuity equation, momentum equation, turbulent kinetic energy equation and turbulent dissipation rate equation. After the steady flow field is obtained by solving the equations for the steady state, the tracer is added to the tundish at the inlet and then the tracer diffusion model is

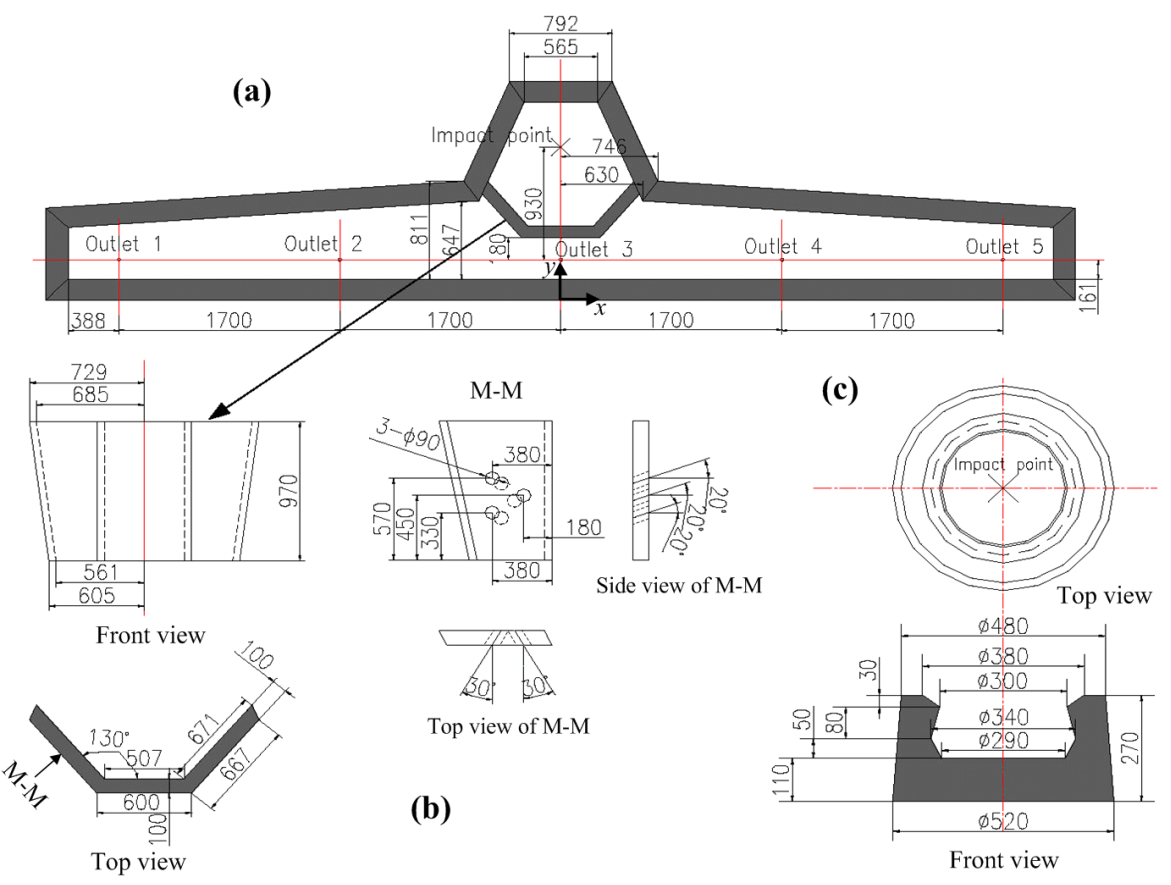

Fig. 1. (a) Schematic top view of plant tundish; (b) Structure and size of U-type baffle with deflector holes; (c) Top and front views of round turbulence inhibitor (Unit: $\mathrm{mm}$ ). (Online version in color.) 
solved for the unsteady state to obtain the tracer concentration field and RTD curve. The specific form and parameters of the above equations are shown in Ref. 10).

This numerical simulation is aimed at the actual tundish, and the geometric model is built according to $1: 1$ ratio by commercial software package Gambit. At the same time, considering the symmetry of the model, in order to reduce the amount of calculation, only a half of the tundish is built, as shown in Fig. 2. In addition, tetrahedron and hexahedron are used to divide the calculation area into grids, and the mesh encryption is carried out at the ladle shroud and the outlets of the tundish. A total of about 1.09 million mesh units are divided.

According to actual flow situation of molten steel in the tundish, the flow boundary conditions of the model are set as follows: (i) the flow velocities of molten steel on all solid surfaces are zero, namely non-slipping conditions at the solid surfaces were applied. (ii) At the symmetry plane in Fig. 2, zero normal gradients of all variables are applied. For the free surface, zero shear stress boundary condition is used. (iii) Near the solid wall, the standard wall function is used as proposed by Launder. ${ }^{17)}$ (iv) The inlet velocity of ladle shroud is assumed to be perpendicular to the free surface and uniform in its transversal section. Boundary conditions of the inlet and the outlet in the tundish are velocity-inlet and outflow, respectively. Based on the conservation of mass, calculation formula of inlet velocity $\left(u_{\text {inlet }}\right)$ is formula (1). The values of turbulent kinetic energy $\left(k_{\text {inlet }}\right)$ and dissipation rate of turbulent kinetic energy $\left(\varepsilon_{\text {inlet }}\right)$ can be calculated by formulas (2) and (3). ${ }^{4}$

$$
\begin{gathered}
u_{\text {inlet }}=\frac{n u_{0} S \rho_{s}}{\frac{\pi}{4} D_{\text {shroud }}^{2} \rho_{L}} \ldots \\
k_{\text {inlet }}=\frac{3}{2} u_{\text {inlet }}^{2} \times 0.0073 \\
\varepsilon_{\text {inlet }}=\frac{k_{\text {inlet }}^{1.5}}{D_{\text {shroud }} / 2} \ldots .
\end{gathered}
$$

Where, $n$ is number of tundish nozzles; $u_{0}$ is the casting speed; $S$ is the area of billet section; $\rho_{s}$ is the density of steel in the liquid-solid two phase coexistence and its value is $7400 \mathrm{~kg} / \mathrm{m}^{3} ; D_{\text {shroud }}$ is the diameter of ladle shroud; $\rho_{L}$ is the density of molten steel and its value is $7014 \mathrm{~kg} / \mathrm{m}^{3}$.

When solving the tracer diffusion model, its solution

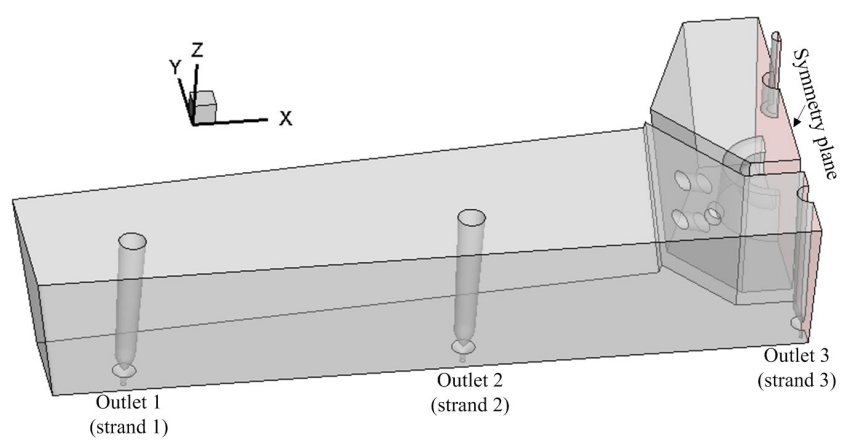

Fig. 2. Geometric model of half tundish for numerical simulation. (Online version in color.) conditions include: physical properties of the tracer are the same with molten steel, and at all the walls, zero concentration gradient is applied. The inlet boundary condition of the tracer mass fraction is stated as follows: At $\mathrm{t} \leq 0.5 \mathrm{~s}$, the tracer mass fraction is set to 1 ; at $\mathrm{t}>0.5 \mathrm{~s}$, the tracer mass fraction is set to 0 . And the time step is $0.5 \mathrm{~s}$ and number of iterations is 5000 .

Based on the above conditions, the mathematical models are solved using the CFD software Fluent 15.0. The computing algorithm is that known as SIMPLE used to solve the
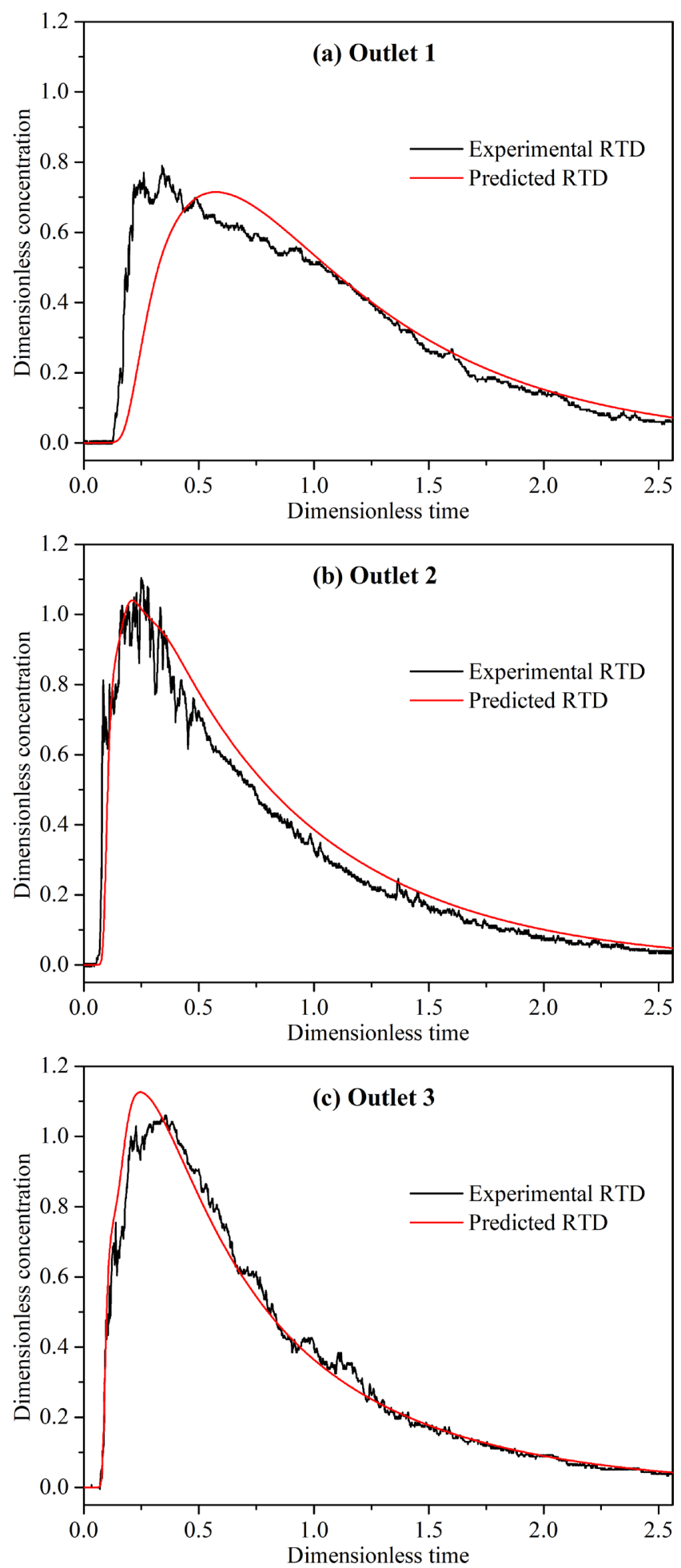

Fig. 3. Comparison of predicted and experimental RTD curves at the outlets of the five-strand tundish. (Online version in color.) 
pressure-velocity coupling. In order to ensure the accuracy of calculation results, the convergence criterion is set to $10^{-6}$ for all the residuals of variables and the discrete format is set as the second order upwind scheme.

\subsection{Validation of Numerical Simulation}

In general, it is difficult to validate directly and accurately mathematical models of high temperature molten steel behavior in real plant tundish. A basic validation of the mathematical models is mainly done with water modeling experiments. In many previous studies, the residence time distribution (RTD) curves are used to compare the numerical simulation results with experimental results. ${ }^{10,18,19)}$ Therefore, in this study the numerical simulation is validated experimentally for a $1 / 3$ scale of the five-strand tundish, and by comparing the RTD curves predicted by numerical simulation and experimental RTD curves, as shown in Fig. 3. The water modeling experiments has been done in the Ref. 10). Dimensionless time and concentration are defined same as in Ref. 10). As can be seen from Fig. 3, the RTD curves predicted by numerical simulation matches well with that of the experimental data. Peaks and tracer response times of the concentration curves for outlet 1 , outlet 2 and outlet 3 matches completely for the experimental and numerical work, and there is slight variation for time to obtain peaks in outlet 1 . The difference in mean residence times predicted by numerical simulation and experimental data at each of the three outlets is found to be less than $0.6 \%$. The validation shows that the results of numerical simulation are reliable, and could be used in the subsequent study.

\section{Results and Discussion}

\subsection{Evaluation Method of Flow Characteristics of Molten Steel in Multistrand Tundish}

At present, evaluation method of flow characteristic of molten steel in single-strand, two-strand and multistrand tundish mainly relies on the RTD curve, so it is clear that whether accurate quantitative analysis of flow characteristics in the tundish can be made depends largely on the RTD curve analysis model, unreasonable analysis model will misjudge flow characteristics in the tundish, and then affect related research results of the tundish. The most widely used tundish RTD curve analysis model is the classical combined model proposed by Sahai. ${ }^{20)}$ The classical combined model is proposed for single-strand tundish. When it is used to the RTD curve analysis of each strand in multistrand tundish, the result tends to have a negative or larger dead region volume fraction, ${ }^{5,9,21,22)}$ which is inconsistent with the actual situation. Therefore, it is unscientific to study overall flow characteristics in a multistrand tundish using the combined model suitable for single-strand tundish RTD curve analysis. Based on the combined model of single-strand tundish RTD curve analysis, many scholars ${ }^{23-29)}$ have also proposed some analysis models that they consider suitable for multistrand tundish. From previous studies, the quantitative research on the flow characteristics in multistrand tundish (such as dead region, short-circuit flow and flow uniformity among multiple strands) is still mainly based on the RTD curve. In this paper, flow field and RTD curve are used together. A new quantitative evaluation method of flow characteristics in multistrand tundish is proposed. The details include the following two aspects.

(1) Specific location and volume fraction of dead region in the tundish could be obtained based on the flow field.

Dead region is not conducive to the exchange of mass and energy, and the floating and removal of inclusions in the tundish, and the homogenization of molten steel temperature and composition. The larger the dead region volume is, the smaller the effective working space is. In chemical reaction engineering, the dead region is defined as the region where average residence time of fluid exceeds twice theoretical average residence time, ${ }^{1)}$ so that the characterization of the dead region appears to be more specific. But in essence, the definition of dead region should actually be the slowly moving area of fluid in the tundish. ${ }^{7,20,25,30)}$ If this slowly moving area can be characterized, it will be more accurate to quantitatively analyze essential characteristics of the dead region. The slowly moving area is the area where the flow velocity is very small. Therefore, in this study, the dead region is defined as the area in the flow field where the velocity is smaller than a certain critical velocity. This critical velocity is called dead region critical velocity $\left(u_{d}\right)$. After this definition, the specific location and volume fraction of the dead region in the tundish could be obtained by the CFD-POST software 15.0. Here, $u_{d}$ is a small flow velocity, and there is no strict determination method. In related optimization studies about tundish, comparison results of the calculated dead region of different schemes is completely credible under the same critical velocity standard.

For the plant tundish involved in this study, when the casting speed of each strand is $1.4 \mathrm{~m} / \mathrm{min}$, its dead region volume at different critical velocities can be determined based on the flow field calculated by numerical simulation, as shown in Table 1. The specific location of the dead region in the tundish can be also obtained. For example, the regions where the flow velocities are less than $0.0030 \mathrm{~m} / \mathrm{s}$, $0.0045 \mathrm{~m} / \mathrm{s}$ and $0.0060 \mathrm{~m} / \mathrm{s}$ respectively are shown in Fig. 4. As can be seen from the figure, the dead region in the tundish is mainly concentrated near the far-strand (namely outlet 1), so the flow characteristic near the far-strand need to be improved. At the same time, for comparison, based on the RTD curves in above operation condition (as shown in Fig. 3), Sahai's classical combination model is also used to calculate the dead region volume fraction of each strand.

Table 1. Volume fraction of tundish dead region under different critical velocities.

\begin{tabular}{cccc}
\hline$u_{d}, \mathrm{~m} / \mathrm{s}$ & $V, \mathrm{~m}^{3}$ & $V_{d}, \mathrm{~m}^{3}$ & $V_{d} / V$ \\
\hline 0.0010 & 2.37191 & 0.004697 & $0.20 \%$ \\
0.0020 & 2.37191 & 0.035644 & $1.50 \%$ \\
0.0030 & 2.37191 & 0.113692 & $4.79 \%$ \\
0.0040 & 2.37191 & 0.233969 & $9.86 \%$ \\
0.0045 & 2.37191 & 0.296558 & $12.50 \%$ \\
0.0050 & 2.37191 & 0.361524 & $15.24 \%$ \\
0.0055 & 2.37191 & 0.433061 & $18.26 \%$ \\
0.0060 & 2.37191 & 0.509141 & $21.47 \%$ \\
\hline
\end{tabular}

Note: $V$ is tundish volume, $V_{d}$ is dead region volume, $V_{d} / V$ is volume fraction of dead region. 
(a)

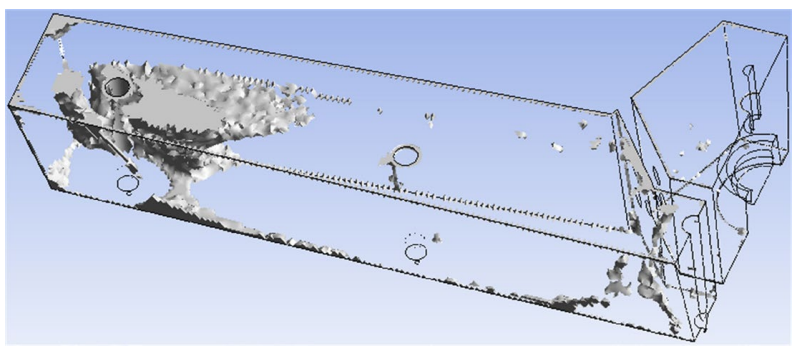

(b)

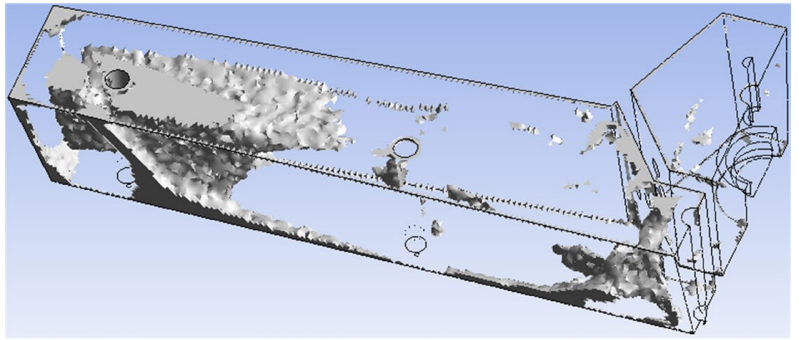

(c)

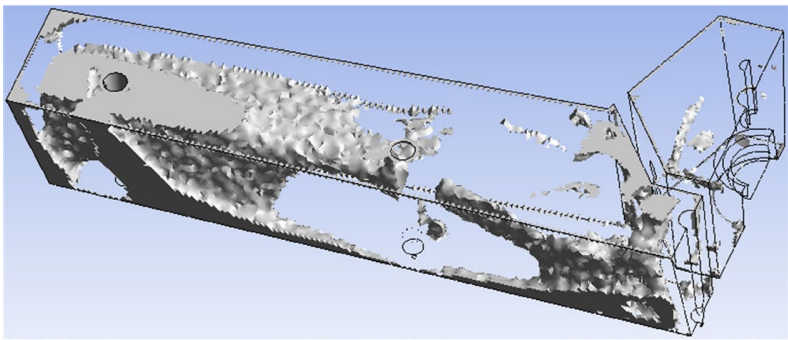

Fig. 4. Three-dimensional visualization of dead region in the plant tundish: (a) The region in which flow velocity is less than $0.0030 \mathrm{~m} / \mathrm{s}$; (b) The region in which flow velocity is less than $0.0045 \mathrm{~m} / \mathrm{s}$; (c) The region in which flow velocity is less than $0.0060 \mathrm{~m} / \mathrm{s}$. (Online version in color.)

And the obtained dead region volume fraction for the farstrand is about $13.99 \%$. The dead region volume fraction for the middle-strand (namely outlet 2) is about $32.93 \%$. The dead region volume fraction for the near-strand (namely outlet 3 ) is about $35.26 \%$. From this result, it is known that not only the dead region volume is too large, but also the dead region volume for the far-strand is the smallest in all strands, which is obviously inconsistent with the case which the molten steel temperature near the far-strand is lower in actual production. In comparison, the calculation results by the method presented in this study show that there are more dead regions near the far-strand. Therefore, it is not appropriate to use Sahai's classical combination model to analyze the flow characteristic in multistrand tundish. The evaluation method of dead region proposed in this study is consistent with actual production, which not only can quantify the dead region, but also can carry out the three-dimensional visual representation for the location of the dead region, more specific and more intuitive.

(2) Based on the RTD curve, the minimum response time $\left(t_{\text {min }}\right)$, peak concentration $\left(C_{p}\right)$, peak concentration time $\left(t_{p}\right)$, actual average residence time $\left(t_{a}\right)$ of each strand tracer and their relative dispersion $(\varphi)$ could be obtained to evaluate the short-circuit flow and flow uniformity among multiple strands in the tundish. Here, the short-circuit flow is a phenomenon in which incoming liquid steel flows rapidly from inlet to outlet. In the short-circuit flow region, the residence time of molten steel in tundish is the shortest, so the inclusion has no time to float up, but directly flows out of the tundish. At the same time, the short-circuit flow has

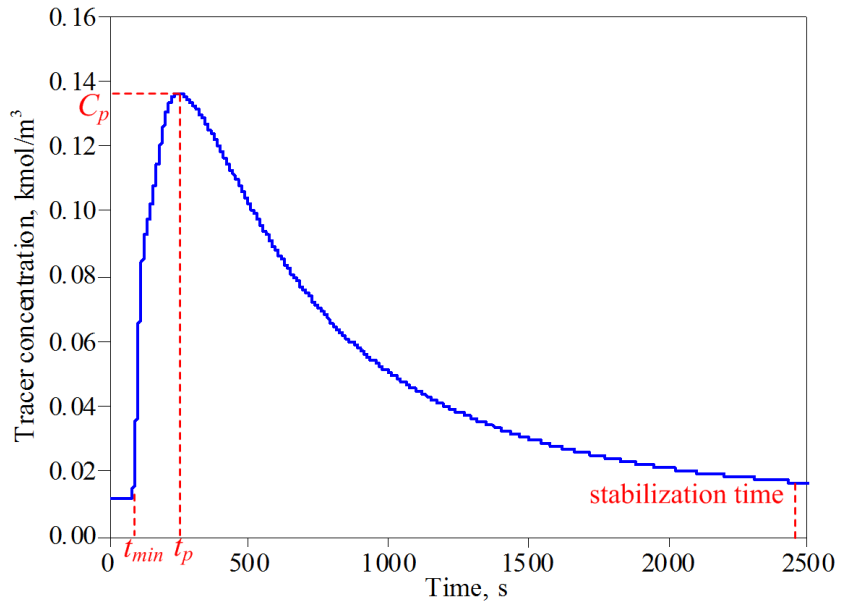

Fig. 5. RTD curve diagram of tundish. (Online version in color.)

little time to exchange mass and energy with other fluids. Obviously, like dead region, the short-circuit flow also reduces the effective working space of tundish and should be avoided as much as possible.

From the RTD curve, the $t_{\min }, C_{p}$ and $t_{p}$ can be directly obtained, as shown in Fig. 5. The smaller the $t_{\min }$ and $t_{p}$ is, the larger the $C_{p}$ is, and the more serious the short-circuit flow in the tundish is. The $t_{a}$ of each strand tracer can be calculated by formula (4) based on the RTD curve data. The $\varphi$ of $t_{\min }, C_{p}, t_{p}$ and $t_{a}$ of strands can be calculated by formula (5). In this study, the $\varphi$ is used to quantitatively analyze the uniformity of flow characteristics in multistrand tundish. According to the theory of statistics, the smaller the $\varphi$ is, the better the flow uniformity among multiple strands is, and the greater the $\varphi$ is, the greater the flow difference among multiple strands is.

$$
\begin{gathered}
t_{a}=\frac{\int_{0}^{\infty} t C(t) d t}{\int_{0}^{\infty} C(t) d t} \ldots \\
\varphi=\sqrt{\frac{\sum_{i=1}^{n}\left(x_{i}-\bar{x}\right)^{2}}{n-1} / \bar{x}}
\end{gathered}
$$

Where, $C(t)$ is tracer concentration at time $t, x_{i}$ is the value of the $i$ th sample (such as $t_{\min }$ of the $i$ th strand, etc.), $\bar{x}$ is arithmetic mean of samples, $n$ is the number of samples (namely the number of the strands studied).

\subsection{Effect of Different Casting Speed Combinations of Strands on Flow Characteristics in the Case of Reducing Throughput}

In actual production, there may be a situation of reducing throughput. In this situation, for multistrand tundish, whether the casting speed of each strand is reduced at the same time, or one strand or two strands is closed or other. If improperly selected, the flow characteristics of molten steel in the tundish will be deteriorated. Therefore, in this study, for the actual five-strand tundish, numerical simulation schemes of Table 2 are designed to investigate the effect of combinations of strands on flow characteristics under the condition of the fixed flow control device, to provide reasonable guidance for reducing throughput. Table 2 shows 
Table 2. Simulation schemes and corresponding boundary conditions.

\begin{tabular}{ccccccccccc}
\hline \multirow{2}{*}{ Cases } & \multicolumn{3}{c}{ Casting speed, $\mathrm{m} / \mathrm{min}$} & \multicolumn{3}{c}{ Velocity-inlet } & \multicolumn{3}{c}{ Outflow, flow rate weighting } & \multirow{2}{*}{$\begin{array}{c}\text { Total steel flux, } \\
\text { ton/min }\end{array}$} \\
\cline { 2 - 9 } & Strand 1 & Strand 2 & Strand 3 & $v_{\text {inlet }}, \mathrm{m} / \mathrm{s}$ & $k, \mathrm{~m}^{2} / \mathrm{s}^{2}$ & $\varepsilon, \mathrm{m}^{2} / \mathrm{s}^{3}$ & Outlet 1 & Outlet 2 & Outlet 3 & \\
\hline 1 & 1.8 & 1.8 & 1.8 & 1.2594 & 0.0174 & 0.0572 & 0.4000 & 0.4000 & 0.2000 & 2.66 \\
2 & 1.4 & 1.4 & 1.4 & 0.9795 & 0.0105 & 0.0269 & 0.4000 & 0.4000 & 0.2000 & 2.07 \\
3 & 1.08 & 1.08 & 1.08 & 0.7556 & 0.0063 & 0.0124 & 0.4000 & 0.4000 & 0.2000 & 1.60 \\
4 & 0 & 1.8 & 1.8 & 0.7556 & 0.0063 & 0.0124 & 0.0000 & 0.6667 & 0.3333 & 1.60 \\
5 & 1.8 & 0 & 1.8 & 0.7556 & 0.0063 & 0.0124 & 0.6667 & 0.0000 & 0.3333 & 1.60 \\
6 & 1.35 & 1.35 & 0 & 0.7556 & 0.0063 & 0.0124 & 0.5000 & 0.5000 & 0.0000 & 1.60 \\
\hline
\end{tabular}

Table 3. Flow characteristics of tundish for different cases in Table 2.

\begin{tabular}{|c|c|c|c|c|c|c|c|}
\hline Cases & Outlet no. & $t_{\min }, \mathrm{s}$ & $C_{p}, \mathrm{kmol} / \mathrm{m}^{3}$ & $t_{p}, \mathrm{~s}$ & $t_{a}, \mathrm{~s}$ & $V_{d} / V\left(\right.$ When $\left.u_{d}=0.004 \mathrm{~m} / \mathrm{s}\right)$ & $V_{d} / V\left(\right.$ When $\left.u_{d}=0.005 \mathrm{~m} / \mathrm{s}\right)$ \\
\hline \multirow{4}{*}{ Case 1} & 1 & 95.5 & 0.1070 & 371.5 & 790.50 & \multirow{4}{*}{$5.02 \%$} & \multirow{4}{*}{$8.96 \%$} \\
\hline & 2 & 54.0 & 0.1455 & 156.5 & 620.01 & & \\
\hline & 3 & 54.5 & 0.1572 & 181.5 & 589.55 & & \\
\hline & $\varphi$ & 0.3503 & 0.1925 & 0.4972 & 0.1625 & & \\
\hline \multirow{4}{*}{ Case 2} & 1 & 145.0 & 0.0817 & 550.5 & 987.93 & \multirow{4}{*}{$9.86 \%$} & \multirow{4}{*}{$15.24 \%$} \\
\hline & 2 & 71.5 & 0.1147 & 203.0 & 745.38 & & \\
\hline & 3 & 71.0 & 0.1242 & 236.5 & 711.63 & & \\
\hline & $\varphi$ & 0.4443 & 0.2089 & 0.5809 & 0.1849 & & \\
\hline \multirow{4}{*}{ Case 3} & 1 & 198.0 & 0.0638 & 775.5 & 1192.59 & \multirow{4}{*}{$16.49 \%$} & \multirow{4}{*}{$24.87 \%$} \\
\hline & 2 & 92.5 & 0.0905 & 263.5 & 875.30 & & \\
\hline & 3 & 92.0 & 0.0971 & 312.0 & 843.97 & & \\
\hline & $\varphi$ & 0.4789 & 0.2103 & 0.6276 & 0.1987 & & \\
\hline \multirow{4}{*}{ Case 4} & 1 & - & - & - & - & \multirow{4}{*}{$21.62 \%$} & \multirow{4}{*}{$29.06 \%$} \\
\hline & 2 & 85.0 & 0.0909 & 276.5 & 862.89 & & \\
\hline & 3 & 85.5 & 0.0892 & 341.5 & 852.34 & & \\
\hline & $\varphi$ & 0.0041 & 0.0134 & 0.1487 & 0.0087 & & \\
\hline \multirow{4}{*}{ Case 5} & 1 & 130.0 & 0.0680 & 638.5 & 1088.80 & \multirow{4}{*}{$14.50 \%$} & \multirow{4}{*}{$21.93 \%$} \\
\hline & 2 & - & - & - & - & & \\
\hline & 3 & 91.5 & 0.0938 & 355.0 & 854.34 & & \\
\hline & $\varphi$ & 0.2458 & 0.2256 & 0.4036 & 0.1706 & & \\
\hline \multirow{4}{*}{ Case 6} & 1 & 154.0 & 0.0686 & 691.0 & 1135.66 & \multirow{4}{*}{$13.66 \%$} & \multirow{4}{*}{$22.15 \%$} \\
\hline & 2 & 90.5 & 0.0875 & 274.5 & 886.72 & & \\
\hline & 3 & - & - & - & - & & \\
\hline & $\varphi$ & 0.3673 & 0.1715 & 0.6101 & 0.1741 & & \\
\hline
\end{tabular}

the casting speed of each strand, corresponding boundary conditions and total steel flux for different schemes. The total steel flux reflects the throughput. In Table 2, cases 1-3 are to investigate the effect of different casting speed levels on the flow characteristics in the case of ensuring the same speed for each strand. Cases 3-6 are to investigate the effect of the situations (such as closing strands 1 and 5, closing strands 2 and 4, closing strand 3 and reducing to the same casting speed for each strand) on flow characteristics in the case of the same total steel flux. Here, it is necessary to explain that the five-strand tundish are symmetrical, so strand 5 is also closed when strand 1 is closed, and strand 4 is also closed when strand 2 is closed, and there is no case of asymmetrical casting when closing one or more strands, as this situation can seriously deteriorate the overall flow characteristic of the tundish.

Firstly, according to the boundary conditions in Table 2, the flow field and RTD curves of the actual tundish for different schemes are calculated by numerical simulation method in Section 3. Then, using evaluation method of flow characteristics in the tundish in Section 4.1, the flow field and RTD curves are further processed, and the results of evaluation parameters of flow characteristics in the tundish for different schemes are obtained, as shown in Table 3. Specific analysis is as follows.

On the one hand, from the results of cases 1-3 in Table 3, 
the flow characteristic parameters $t_{\min }, C_{p}, t_{p}$ and $t_{a}$ of strand 1 (far-strand) for each case are different with that of strands 2 and 3 under the condition that the casting speed of each strand is the same. In all the strands, the $t_{\min }, t_{p}$ and $t_{a}$ of strand 1 are longer and its $C_{p}$ is lower, which indicates that the molten steel flow of strand 1 is slower than that of other strands. This is consistent with the conclusion that dead zone near the far-strand is larger in Fig. 4 (corresponding to case 2). The flow characteristic parameters $t_{\min }, C_{p}, t_{p}$ and $t_{a}$ of strands 2 and 3 are very close. At the same time, from the comparison of the results of cases 1-3, the smaller the casting speed is, that is, the smaller the total steel flux is, the longer the $t_{\min }, t_{p}$ and $t_{a}$ of each strand are, and its $C_{p}$ is reduced to some extent, which indicates that the phenomenon of short-circuit flow in the tundish is weakened, but the $\varphi$ of the parameters $t_{\min }, C_{p}, t_{p}$ and $t_{a}$ of strands become larger and larger, and the dead region volume also becomes larger and larger. Compared with case 1 (the casting speed of each strand is $1.8 \mathrm{~m} / \mathrm{min}$ ), case 3 is under the low speed of $1.08 \mathrm{~m} / \mathrm{min}$ for each strand and its dead region volume fraction increases by $11.47 \%$ (When $u_{d}=0.004 \mathrm{~m} / \mathrm{s}$ ) or $15.91 \%$ (When $u_{d}=0.005 \mathrm{~m} / \mathrm{s}$ ), which is very unfavorable for the flow of molten steel in the tundish. Therefore, in the case of reducing the throughput, when the casting speed of each strand is reduced at the same time, although the shortcircuit phenomenon is weakened, the difference of flow characteristics among multiple strands becomes larger, and the dead region volume in the entire tundish also increases significantly.

On the other hand, when the throughput needs to be reduced to the same level of 1.60 ton/min, different schemes are analyzed according to the results of cases 3-6 in Table 3 . Firstly, from the comparison of dead region volume fractions, the dead region volume of case 4 (closing strands 1 and 5) is the largest, the one of case 3 (reducing to the same casting speed for each strand) is the second, the dead region volume of case 5 (closing strands 2 and 4 ) and case 6 (closing strand 3 ) are smaller. The flow near the far-strand itself is slower, and the dead region volume is larger. If farstrand is closed according to case 4 , the dead region proportion will be further increased. So the case 4 should first be excluded when selecting schemes to reduce the throughput. Secondly, from the comparison of the $t_{\min }, C_{p}, t_{p}, t_{a}$ and $\varphi$ for case 3 , case 5 and case 6 , it can be seen that the flow uniformity among multiple strands is very different, and the flow characteristics' difference for case 3 is larger, the flow characteristics' difference for case 5 or case 6 is relatively smaller. Case 5 actually becomes a symmetric three-strand casting, and case 6 becomes a symmetric four-strand cast- ing. Considering production cost, it is more economical and reasonable to use case 5 (closing strands 2 and 4) when reducing throughput.

\subsection{Effect of Increasing Far-strand's Casting Speed on Flow Characteristics}

For the inner structure of the tundish in Fig. 1, it can be seen from the above analysis that not only the molten steel flow near the far-strand is slower and the dead region volume is larger, but also the difference of flow characteristics between the far-strand and other strands is also larger. Aiming at the problems, and under the condition of the fixed flow control device, this study tries to further improve the overall flow characteristic of the tundish by increasing the far-strand's casting speed. The corresponding numerical simulation schemes are designed, as shown in Table 4. In Table 4, cases 2-5 are to investigate the effect of the situation which the casting speed of strands 1 and 5 (far-strands) is increased while the casting speeds of other strands remain unchanged on flow characteristics. This situation will bring the increase of total steel flux. Cases 1 and 5 are under the same total steel flux and to investigate the effect of the situation which the casting speeds of strands 1 and 5 are larger while the casting speeds of other strands are smaller and the same on flow characteristics. Here, it is necessary to explain that considering the five-strand tundish are symmetrical, Table 4 shows only the related parameters of strands $1-3$.

Firstly, according to the boundary conditions in Table 4, the different schemes are numerically simulated. And then, based on the obtained flow field and RTD curve of the tundish, flow characteristics in the tundish are analyzed by the method in Section 4.1. The results are shown in Table 5.

From the results of cases $2-5$ in Table 5, when the casting speed of strand 1 is increased from $1.08 \mathrm{~m} / \mathrm{min}$ to 1.88 $\mathrm{m} / \mathrm{min}$ and the corresponding total steel flux is increased from $1.60 \mathrm{ton} / \mathrm{min}$ to $2.07 \mathrm{ton} / \mathrm{min}$, the $t_{\min }, t_{p}$ and $t_{a}$ of each strand are somewhat reduced, and $C_{p}$ is somewhat increased, which indicates that the phenomenon of shortcircuit flow in the tundish is somewhat enhanced, and the $\varphi$ of the parameters $t_{\min }, C_{p}, t_{p}$ and $t_{a}$ of strands are reduced by $19.66 \%, 2.64 \%, 11.31 \%$, and $4.60 \%$ respectively, which indicates that the uniformity of flow characteristics among multiple strands is greatly improved. It can also be seen that as the casting speed of strand 1 increases from $1.08 \mathrm{~m} / \mathrm{min}$ to $1.88 \mathrm{~m} / \mathrm{min}$, the dead region volume fraction decreases by $8.70 \%$ (when $u_{d}=0.004 \mathrm{~m} / \mathrm{s}$ ) or $11.57 \%$ (when $u_{d}=0.005$ $\mathrm{m} / \mathrm{s}$ ), and the dead region is significantly reduced. From the above analysis, while the casting speeds of other strands remain unchanged, increasing the far-strand's casting speed

Table 4. Simulation schemes and corresponding boundary conditions.

\begin{tabular}{|c|c|c|c|c|c|c|c|c|c|c|}
\hline \multirow{2}{*}{ Cases } & \multicolumn{3}{|c|}{ Casting speed, $\mathrm{m} / \mathrm{min}$} & \multicolumn{3}{|c|}{ Velocity-inlet } & \multicolumn{3}{|c|}{ Outflow, flow rate weighting } & \multirow{2}{*}{$\begin{array}{l}\text { Total steel flux, } \\
\text { ton/min }\end{array}$} \\
\hline & Strand 1 & Strand 2 & Strand 3 & $v_{\text {inlet }}, \mathrm{m} / \mathrm{s}$ & $k, \mathrm{~m}^{2} / \mathrm{s}^{2}$ & $\varepsilon, \mathrm{m}^{2} / \mathrm{s}^{3}$ & Outlet 1 & Outlet 2 & Outlet 3 & \\
\hline 1 & 1.40 & 1.40 & 1.40 & 0.9795 & 0.0105 & 0.0269 & 0.4000 & 0.4000 & 0.2000 & 2.07 \\
\hline 2 & 1.08 & 1.08 & 1.08 & 0.7556 & 0.0063 & 0.0124 & 0.4000 & 0.4000 & 0.2000 & 1.60 \\
\hline 3 & 1.30 & 1.08 & 1.08 & 0.8172 & 0.0073 & 0.0156 & 0.4452 & 0.3699 & 0.1849 & 1.73 \\
\hline 4 & 1.60 & 1.08 & 1.08 & 0.9011 & 0.0089 & 0.0210 & 0.4969 & 0.3354 & 0.1677 & 1.91 \\
\hline 5 & 1.88 & 1.08 & 1.08 & 0.9795 & 0.0105 & 0.0269 & 0.5371 & 0.3086 & 0.1543 & 2.07 \\
\hline
\end{tabular}


ISIJ International, Vol. 59 (2019), No. 7

Table 5. Flow characteristics of tundish for different cases in Table 4.

\begin{tabular}{|c|c|c|c|c|c|c|c|}
\hline Cases & Outlet no. & $t_{\min }$ & $C_{p}$ & $t_{p}$ & $t_{a}$ & $V_{d} / V\left(\right.$ When $\left.u_{d}=0.004 \mathrm{~m} / \mathrm{s}\right)$ & $V_{d} / V\left(\right.$ When $\left.u_{d}=0.005 \mathrm{~m} / \mathrm{s}\right)$ \\
\hline \multirow{4}{*}{ Case 1} & 1 & 145.0 & 0.0817 & 550.5 & 987.93 & \multirow{4}{*}{$9.86 \%$} & \multirow{4}{*}{$15.24 \%$} \\
\hline & 2 & 71.5 & 0.1147 & 203.0 & 745.38 & & \\
\hline & 3 & 71.0 & 0.1242 & 236.5 & 711.63 & & \\
\hline & $\varphi$ & 0.4443 & 0.2089 & 0.5809 & 0.1849 & & \\
\hline \multirow{4}{*}{ Case 2} & 1 & 198.0 & 0.0638 & 775.5 & 1192.59 & \multirow{4}{*}{$16.49 \%$} & \multirow{4}{*}{$24.87 \%$} \\
\hline & 2 & 92.5 & 0.0905 & 263.5 & 875.30 & & \\
\hline & 3 & 92.0 & 0.0971 & 312.0 & 843.97 & & \\
\hline & $\varphi$ & 0.4789 & 0.2103 & 0.6276 & 0.1987 & & \\
\hline \multirow{4}{*}{ Case 3} & 1 & 160.0 & 0.0705 & 669.0 & 1106.55 & \multirow{4}{*}{$13.63 \%$} & \multirow{4}{*}{$21.17 \%$} \\
\hline & 2 & 83.5 & 0.0976 & 242.0 & 833.29 & & \\
\hline & 3 & 82.5 & 0.1050 & 283.0 & 802.13 & & \\
\hline & $\varphi$ & 0.4091 & 0.1993 & 0.5919 & 0.1833 & & \\
\hline \multirow{4}{*}{ Case 4} & 1 & 135.0 & 0.0791 & 556.0 & 1006.08 & \multirow{4}{*}{$10.49 \%$} & \multirow{4}{*}{$16.95 \%$} \\
\hline & 2 & 76.0 & 0.1069 & 218.0 & 781.81 & & \\
\hline & 3 & 75.5 & 0.1163 & 251.5 & 748.09 & & \\
\hline & $\varphi$ & 0.3582 & 0.1922 & 0.5448 & 0.1659 & & \\
\hline \multirow{4}{*}{ Case 5} & 1 & 110.5 & 0.0872 & 482.5 & 927.71 & \multirow{4}{*}{$7.79 \%$} & \multirow{4}{*}{$13.30 \%$} \\
\hline & 2 & 70.0 & 0.1155 & 199.0 & 737.77 & & \\
\hline & 3 & 69.5 & 0.1263 & 228.0 & 704.04 & & \\
\hline & $\varphi$ & 0.2823 & 0.1839 & 0.5145 & 0.1527 & & \\
\hline
\end{tabular}

can significantly reduce the dead region proportion and the flow difference among multiple strands, but comparatively the phenomenon of short-circuit flow may be enhanced. As total steel flux increases, the flow velocity of molten steel increases, and so the enhancement of short circuit flow is inevitable.

At the same time, from the results of cases 1 and 5 in Table 5, under the same total steel flux of $2.07 \mathrm{ton} / \mathrm{min}$, flow characteristic parameters (such as $t_{\min }, C_{p}, t_{p}$ and $t_{a}$ ) of strands 2 and 3 for case 1 is close to those for case 5, which indicates that the short-circuit flow in the tundish does not change much. Compared with case 1 (namely the casting speed of each strand is $1.40 \mathrm{~m} / \mathrm{min}$ ), the difference of $t_{\min }, C_{p}, t_{p}$ and $t_{a}$ between strand 1 and other two strands for case 5 (namely the casting speed of strand 1 is $1.88 \mathrm{~m}$ / $\min$ and those of strands 2 and 3 are $1.08 \mathrm{~m} / \mathrm{min}$ ) is reduced to some extent, and especially the $\varphi$ of $t_{\min }$ is reduced by $16.20 \%$, the $\varphi$ of $C_{p}, t_{p}$ and $t_{a}$ is also reduced, and the dead region volume fraction is also reduced. These results show that in the case of the same total steel flux, the short-circuit flow in the tundish does not change much, and the increase of far-strand's casting speed can reduce the flow difference among multiple strands and dead region proportion.

In addition, it can be found from Table 5 that the total steel flux increases from $1.60 \mathrm{ton} / \mathrm{min}$ to $2.07 \mathrm{ton} / \mathrm{min}$ by either from case 2 to case 1 , or from case 2 to case 5 . The former is to increase the casting speed of each strand from $1.08 \mathrm{~m} / \mathrm{min}$ to $1.40 \mathrm{~m} / \mathrm{min}$, and the latter is to only increase the casting speed of strand 1 from $1.08 \mathrm{~m} / \mathrm{min}$ to $1.88 \mathrm{~m} /$ min. Comparing flow characteristics of the two changes, it can be seen that the short-circuit flow has not changed much. But comparing the latter with the former, the reductions for the $\varphi$ of flow characteristic parameters (such as $t_{\text {min }}$, $C_{p}, t_{p}$ and $t_{a}$ ) of strands and dead region volume fraction are more large, which indicates that the latter can more significantly reduce the dead region proportion and flow difference among multiple strands. In other words, in the case of increasing the same throughput, the flow characteristics in the tundish for only increasing the far-strand's casting speed are better than that for increasing the casting speed of each strand simultaneously.

\section{Conclusions}

This paper gives a detailed numerical investigation for the effect of casting speed on flow characteristics of molten steel in a plant five-strand tundish. Firstly, aiming at the characteristics of multistrand tundish and based on past research, a quantitative evaluation method of flow characteristics in multistrand tundish is proposed from the aspects of dead region, short-circuit flow and flow uniformity among multiple strands. Then, using the method, this paper investigates the effect of different casting speed combinations of strands on flow characteristics in the case of reducing throughput, and the effect of increasing far-strand's casting speed on flow characteristics. And the following conclusions have been drawn:

(1) The evaluation method of flow characteristics in multistrand tundish includes: on the one hand, based on flow field of numerical simulation, an evaluation method of dead region in multistrand is presented. When the dead region is defined as the area in the flow field where the velocity is 
smaller than a certain critical velocity, specific location and volume fraction of the dead region in the tundish could be obtained. And the method and Sahai's combination model are used to analyze the dead region in the plant tundish. By comparison, the result of the method proposed in this paper is consistent with the actual situation. On the other hand, based on the calculated RTD curve, the minimum response time, peak concentration, peak concentration time, actual average residence time of each strand tracer and their relative dispersion are obtained to evaluate the short-circuit flow and flow uniformity among multiple strands in the tundish.

(2) In the case of reducing throughput, six numerical simulation schemes are designed to investigate the effect of the situations (such as reducing to the same casting speed for each strand, closing one or two strands or other conditions) on flow characteristics in the multistrand tundish. The results show that when the casting speed of each strand is reduced at the same time, although the short-circuit phenomenon is weakened, the difference of flow characteristics among multiple strands becomes larger, and the dead region volume in the entire tundish also increases significantly. At the same time, when the throughput needs to be reduced to the same level, for the four schemes (closing strands 1 and 5, closing strands 2 and 4, closing strand 3 and reducing to the same casting speed for each strand), the scheme of closing strands 2 and 4 has the best flow characteristics, and not only the dead region volume is smaller, but also the flow difference among multiple strands is also smaller, and it becomes a symmetric three-strand casting and is also the most economical in terms of production costs. Therefore, when reducing throughput, it is recommended to close the strands 2 and 4.

(3) In view of slower flow and bigger dead region near the far-strand of the five-strand tundish and large difference for flow characteristics between the far-strand and other strands, five numerical simulation schemes are designed to investigate the effect of increasing the far-strand's casting speed on improving the overall flow characteristic in the tundish in the case where the total steel flux increases and remains the same. The results show that, increasing the far-strand's casting speed can significantly reduce the dead region proportion and flow difference among multiple strands, and in the case of the same total steel flux, the shortcircuit flow does not change much. In addition, it is also found that in the case of increasing the same throughput, the flow characteristics in the tundish for only increasing the far-strand's casting speed are better than that for increasing the casting speed of each strand simultaneously.

\section{Acknowledgements}

This research is supported by the National Natural Science Foundation of China (51504002).

\section{REFERENCES}

1) Y. Sahai and T. Emi: Tundish Technology for Clean Steel Production, World Scientific, Singapore, (2007), 99.

2) J. J. Wang, Y. P. Bao and Y. Qu: Tundish Metallurgy, Metallurgical Industry Press, Beijing, (2001), 84.

3) K. Chattopadhyay, M. Isac and R. I. L. Guthrie: ISIJ Int., 50 (2010), 331 .

4) R. D. Morales, J. Barreto, S. Lopez-Ramirez, J. Palafox-Ramos and D. Zacharias: Metall. Mater. Trans. B, 31 (2000), 1505.

5) L. C. Zhong, B. K. Li, Y. X. Zhu, R. G. Wang, W. Z. Wang and X. J. Zhang: ISIJ Int., 47 (2007), 88.

6) A. Espino-Zarate, R. D. Morales, A. Najera-Bastida, M. J. MacíasHernández and A. Sandoval-Ramos: Metall. Mater. Trans. B, 41 (2010), 962.

7) A. Tripathi and S. K. Ajmani: ISIJ Int., 51 (2011), 1647.

8) K. Chattopadhyay, M. Isac and R. I. L. Guthrie: Ironmaking Steelmaking, 39 (2012), 454.

9) T. Merder and M. Warzecha: Metall. Mater. Trans. B, 43 (2012), 856.

10) F. He, L. Y. Zhang and Q. Y. Xu: China Foundry, 13 (2016), 166.

11) A. Cwudziński: Arch. Metall. Mater., 59 (2014), 1249.

12) K. Raghavendra, S. Sarkar, S. K. Ajmani, M. B. Denys and M. K. Singh: Appl. Math. Model., 37 (2013), 6284.

13) L. C. Zhong, M. A. Wang, B. Y. Chen, C. R. Wang and Y. X. Zhu: J. Iron Steel Res. Int., 17 (2010), 7.

14) S. K. Mishra, P. K. Jha, S. C. Sharma and S. K. Ajmani: Can. Metall. Q., 51 (2012), 170.

15) A. Sengupta, P. Mishra, V. Singh, S. Mishra, P. K. Jha, S. K. Ajmani and S. C. Sharma: Ironmaking Steelmaking, 40 (2013), 159.

16) T. Merder: Arch. Metall. Mater., 59 (2014), 887.

17) B. E. Launder and D. B. Spalding: Comput. Method. Appl. Mech. Eng., 3 (1974), 269.

18) V. Singh, A. R. Pal and P. Panigrahi: ISIJ Int., 48 (2008), 430.

19) S. K. Mishra, P. K. Jha, S. C. Sharma and S. K. Ajmani: Int. J. Miner. Metall. Mater., 18 (2011), 535.

20) Y. Sahai and T. Emi: ISIJ Int., 36 (1996), 667.

21) S. Chang, L. C. Zhong and Z. S. Zou: ISIJ Int., 55 (2015), 837.

22) A. Kumar, D. Mazumdar and S. C. Koria: ISIJ Int., 48 (2008), 38.

23) J. J. Wang, S. H. Peng and Z. Q. Xiao: Steelmaking, 5 (1998), 27.

24) S. G. Zheng and M. Y. Zhu: Acta Metall. Sin., 41 (2005), 1073.

25) H. W. Pan and S. S. Cheng: Acta Metall. Sin., 22 (2009), 297.

26) H. Lei, Y. Zhao, J. L. Bao, C. J. Liu, H. G. Chen and J. C. He: Acta Metall. Sin., 46 (2010), 1109.

27) H. Lei: Metall. Mater. Trans. B, 46 (2015), 2408.

28) D. X. Li and H. Cui: Chin. J. Eng., 38 (2016), 41.

29) X. F. Su, Y. L. Ji, J. H. Liu, Y. He, S. B. Shen and H. Cui: Steel Res. Int., 89 (2018), 1800085. https://doi.org/10.1002/srin.201800085

30) M. Tomasz and P. Jacek: Steel Res. Int., 83 (2012), 1029. 